\title{
RELIGIOUS PLURALISM IN INDONESIA
}


A volume in the series

Cornell Modern Indonesia Project

Edited by Eric Tagliacozzo and Thomas B. Pepinsky

A list of titles in this series is available at cornellpress.cornell.edu. 


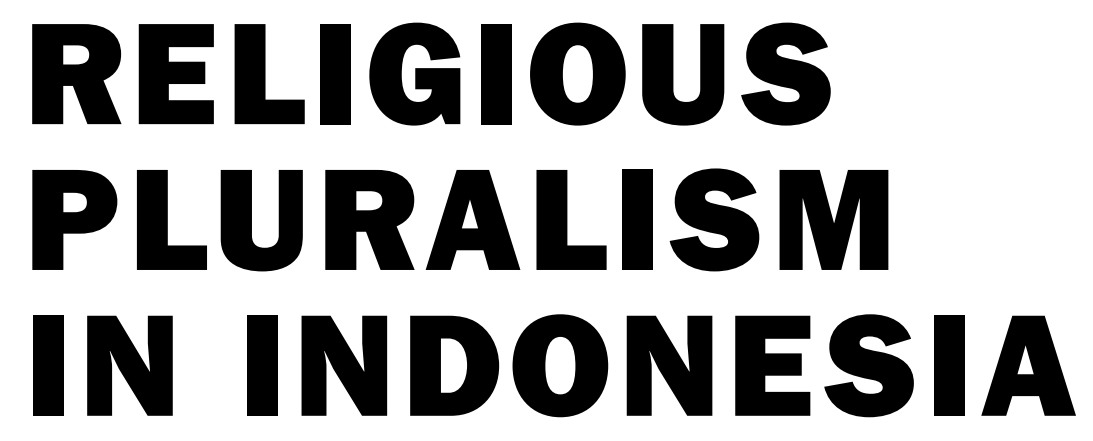

Threats and Opportunities for Democracy

Edited by Chiara Formichi 


\section{Copyright ( 2021 by Cornell University}

All rights reserved. Except for brief quotations in a review, this book, or parts thereof, must not be reproduced in any form without permission in writing from the publisher. For information, address Cornell University Press, Sage House, 512 East State Street, Ithaca, New York 14850. Visit our website at cornellpress.cornell.edu.

First published 2021 by Cornell University Press

Library of Congress Cataloging-in-Publication Data

Names: Formichi, Chiara, 1982- editor.

Title: Religious pluralism in Indonesia : threats and opportunities for democracy / edited by Chiara Formichi.

Description: Ithaca [New York] : Southeast Asia Program Publications, an imprint of Cornell University Press, 2021. | Series: Cornell Modern Indonesia Project | Contributions from a conference held at Cornell University in April 2019. | Includes bibliographical references and index.

Identifiers: LCCN 2021007714 (print) | LCCN 2021007715 (ebook) | ISBN 9781501760433 (hardcover) | ISBN 9781501760440 (paperback) | ISBN 9781501760457 (epub) | ISBN 9781501760464 (pdf)

Subjects: LCSH: Religious pluralism-Indonesia-History20th century-Congresses. | Religious tolerance-Indonesia-History20th century-Congresses. | Pancasila-Congresses. | Religion and state-Indonesia-History-20th century-Congresses. | ReligionsRelations-History-20th century-Congresses. | Indonesia-ReligionHistory-20th century-Congresses.

Classification: LCC BL2112 .R458 2021 (print) | LCC BL2112 (ebook) | DDC 201/.50959809045-dc23

LC record available at https://lccn.loc.gov/2021007714

LC ebook record available at https://lccn.loc.gov/2021007715

Cover art: The Kwang Kong statue. () Evi Sutrisno. 